\title{
Dietary phytate intake inhibits the bioavailability of iron and calcium in the diets of pregnant women in rural Bangladesh: a cross-sectional study
}

Syed Mahfuz Al Hasan*, Mahedi Hassan, Sonjoy Saha, Mominul Islam, Masum Billah and Shimul Islam

\begin{abstract}
Background: Phytate, a potent inhibitor of calcium, iron, and zinc absorption, may hamper the bioavailability of these micronutrients at the time of pregnancy. This study assessed dietary phytate intake and its inhibitory effect on the bioavailability of calcium, iron, and zinc from the diets of pregnant women in rural Bangladesh. The study also explored significant determinants that predicted the absorption of these minerals from the diet.
\end{abstract}

Methods: A multiple pass recall (MPR) approach was used for this study, with in-depth probing interview covering 24-h dietary recall conducted among 717 pregnant women who were in either their second or third trimester.

Results: The mean daily phytate, calcium, iron and zinc intake of the pregnant women were found to be 695.1, $192.2,5.1$, and $5.7 \mathrm{mg}$ respectively. The mean molar ratios of phytate to calcium, iron, zinc and (phytate $x$ calcium)/zinc were $0.27,12.8,11.2$, and 54.8 respectively. All the molar ratios were found to be significantly higher in a group with the highest phytate intake compared to other intake groups. Phytate inhibited iron absorption from the diet of all the pregnant women sampled, and inhibited calcium absorption among $52 \%$ of the women while inhibition of zinc absorption was not found in a notable number (12\%) of the pregnant women. When using multivariate models, phytate intake, inadequate micronutrient intake, gestational age, and energy intake significantly predicted the variance in phytate to mineral molar ratios. The predicting models calculated about $92 \%, 88 \%$, and $89 \%$ variance in phytate to calcium, iron, and zinc molar ratios respectively. Phytate to calcium, iron, and zinc molar ratios would be expected to be respectively $0.05,2.48$, and 1.96 points higher for every $100 \mathrm{mg}$ increment in daily phytate intake.

Conclusions: Phytate intake was found to inhibit the bioavailability of iron and calcium from the diets of pregnant women. Moreover, phytate was one of the strongest inhibitory predictors of calcium, iron and zinc bioavailability.

Keywords: Phytate intake, Molar ratios, Bioavailability, Pregnant women, Bangladesh

\footnotetext{
* Correspondence: mahfuz.alhasan@yahoo.com

Department of Nutrition and Food Technology, Jessore University of Science and Technology, Jessore 7408, Bangladesh
}

(c) 2016 Al Hasan et al. Open Access This article is distributed under the terms of the Creative Commons Attribution 4.0 


\section{Background}

Pregnant women are predominantly susceptible to nutritional deficiencies because of the increased metabolic demands imposed by pregnancy and its related factors [1]. Nutritional deficiency, particularly micronutrient deficiency, at the time of pregnancy contributes to avoidable adverse birth outcomes [2]. Iron and calcium deficiencies during pregnancy contribute significantly to maternal deaths, while iron deficiency is also associated with low birth weight [3]. Furthermore, maternal zinc deficiency results in consequences ranging from fetal death to intrauterine growth retardation [4].

A systematic review on micronutrient intake among pregnant women in resource-poor settings reveals that inadequate zinc and iron intake were reported in $92 \%$ and $78 \%$ of studies respectively [5]. Inadequate intake of iron, zinc, and calcium are also reported among pregnant women in rural South Asia [6-9].

The available literature on Bangladesh has shown the inadequacy of calcium, iron and zinc intake among women. About $63 \%$ of Bangladeshi women in the low-income group have inadequate calcium intake [10]. Besides the inadequate intake of calcium, available studies have shown low to marginal levels of serum calcium in the pregnant women of Bangladesh [11-13]. Meanwhile, the recent Bangladesh National Micronutrient Status Survey [14] reported inadequate daily zinc $(3.9 \mathrm{mg})$ and iron $(7.2 \mathrm{mg})$ intake among rural women. This survey also highlights a nationwide high prevalence of zinc deficiency ( $57.5 \%$ ) but low iron deficiency $(7.1 \%)$ among rural women. Some other recent studies from Bangladesh have reported iron deficiency among the rural women from $0.0 \%$ [15] to $11.0 \%[16]$.

Inadequate micronutrient intake and predominantly plant-based diets are very common dietary features of pregnant women in developing countries like Bangladesh, where rice contributes around $80 \%$ of dietary energy [17]. Plant-based diets in developing countries are usually high in phytate, which inhibits mineral absorption [18]. The inhibitory effect of phytate on calcium, iron, and zinc absorption has been established by in vivo as well as community-based studies [19-25].

To our knowledge, there is no study which reports the phytate intake in the diets of pregnant women in Bangladesh and assesses the effect of phytate on the bioavailability of minerals. This study focuses on the inhibitory effects of phytate on calcium, iron and zinc bioavailability from the diets of pregnant women in rural Bangladesh. Moreover, the study aims to find out the possible determinants that could significantly predict the bioavailability of calcium, iron, and zinc from these diets.

\section{Methods}

\section{Sampling}

The study used a cross-sectional, multi-stage dietary intake survey, which was designed to concentrate on the effect of dietary phytate on calcium, iron and zinc bioavailability from the diets of economically vulnerable pregnant women from rural areas in 8 sub-districts of 3 southern districts of Bangladesh, namely Jessore, Khulna and Sathkhira. The selection of pregnant women from those 8 sub-districts was limited to those in their $2^{\text {nd }}$ or $3^{\text {rd }}$ trimesters and from economically vulnerable households.

The pregnant women were selected using a multistage cluster sampling design. For the first stage of sampling, within each of the 8 sub-districts, numbers of clusters were selected based on the numbers of community clinics (CC) in those sub-districts. The number of clusters varied from 23 to 58 clusters in Jessore district, 17 to 19 clusters in Khulna district, and 34 to 37 clusters in Sathkhira district. In each case, the community clinic was regarded as the center of the cluster. Considering the selection criteria, a sampling frame (lists of the pregnant women with name, occupation of the household head, trimester information, and detailed address) of pregnant women was constructed for each of the 8 subdistricts with the help of local personnel from the CCs during May to July 2014.

At the second stage of sampling, 90 pregnant women were randomly selected from the lists for each of the subdistricts. A total of 720 pregnant women from 253 clusters within the 8 sub-districts were selected for this study.

Among the selected pregnant women, two were not available in three consecutive visits to their home, and one of them denied participating in the study, thus this investigation ended up using a sample 717 pregnant women in their second and third trimesters.

\section{Dietary intake assessment}

Dietary intake of the pregnant women was assessed at their respective homes, by undergraduate thesis students of the Department of Nutrition and Food Technology of Jessore University of Science and Technology, Bangladesh. Those students were trained in retrieving dietary data through the 24-h dietary recall and weighing methods.

A pretested and structured questionnaire for dietary data collection was used in this study (Additional file 1). The information on dietary intake of the pregnant women was collected by conducting a 24-h dietary recall through an in-depth neutral verbal probing interview, with the help of multiple pass recall, a staged approach to the dietary recall method [26]. This method supports respondents to recall their intake in a free and uninterrupted way, followed by detailed and probing questions about intake, as this improves the quality of dietary data 
[27]. This method is also validated as an accurate method for estimating total energy and nutrient intake in women [28].

The amount of food consumed by a pregnant woman was estimated using standard measuring cups, spoons and weighing machines that were provided to the interviewers. When there was confusion about the local servings of the recalled food, the local servings were adjusted with the standard measuring cups, and amounts were measured by weighing them as well. This weighing was done as the pregnant women were asked to take the same amount of food in their household serving as the amount they consumed in the recalled day. The weighing of cooked food, particularly for rice, was also undertaken. The weighing was undertaken using electronic balances $( \pm 10 \mathrm{~g}$; TANITA KD 182).

\section{Phytate content of foods and mineral intake}

Data on phytate content of different foods consumed by the pregnant women were derived from the recent food composition table (FCT) compiled for Bangladesh [29]. Phytate content of foods that were not available in the FCT of Bangladesh was taken from other published data [30-33]. The phytate, calcium, iron, and zinc intake of the pregnant women were calculated using the dietary recall data. Dietary data collected from the 24-h dietary assessment was coded and linked to the FCT database. To convert the amount of consumed foods per pregnant woman into energy, calcium, iron, and zinc intake, corresponding values from the FCT of Bangladesh [29] were used. Weight changes during food preparation were adjusted by using yield factors for each of the cooked foods consumed by the pregnant women. Mineral content of the cooked foods were derived from the FCT of Bangladesh and losses of minerals during cooking were adjusted using nutrient retention factors [29].

\section{Molar ratios and quintiles of phytate intake}

In this study, phytate to minerals molar ratios was used to estimate the inhibitory effects of phytate on the bioavailability of minerals from the consumed diets of the pregnant women $[18,19,23,25]$. The inhibitory effect of dietary phytate on the bioavailability of calcium, iron, and zinc from the diet of the pregnant women were measured through phytate to calcium, iron, and zinc molar ratios respectively. The percentages of pregnant women with molar ratios above the suggested cut-off values for inhibition were calculated. Phytate might be exerting its inhibitory effect on the bioavailability of calcium, iron, and zinc from the diet of those pregnant women who had molar ratios above the cut-off points. The recommended critical values are as follows: (phytate to calcium) $>0.24$ for calcium [34], (phytate to iron) $>1$ for iron [35], (phytate to zinc) $>15$ for zinc [36], and (phytate $\times$ calcium)/zinc $>200$ for the combined effect of phytate and calcium on zinc [37] were used in this study. The molar ratios of phytate to zinc, calcium, and iron are calculated as the millimoles of phytate intake per day divided by the millimoles of zinc, calcium, and iron intake per day, respectively. The (calcium $\times$ phytate) to zinc molar ratio is expressed as millimoles per day.

The pregnant women were categorised into quintiles according to their phytate intake, through arranging them in ascending order from lowest to highest intake. Women in the $1^{\text {st }}$ quintile therefore displayed the lowest phytate intake, and women in the $5^{\text {th }}$ quintile had the highest phytate intake.

\section{Statistical analysis}

Normal probability plots, $Z_{\text {skewness }}$ and $Z_{\text {kurtosis, }}, Q-Q$ plots, box plots, and the Shapiro-Wilk test were used on the consumption data to investigate whether phytate, calcium, iron, and zinc intakes variables followed a normal distribution [38]. Descriptive statistical tests were applied to socio-demographic and gestational variables. The mean and $95 \%$ confidence interval (CI) were used to express the phytate intake data and the molar ratios. Analysis of variance (ANOVA) was applied to GamesHowell post hoc comparisons to compare the differences in phytate intake and the molar ratios across the different phytate intake quintiles.

Multiple linear regression analyses were conducted to look at determinants of phytate to minerals molar ratios. Covariates that may explain the variance in molar ratios (dependent variables) were included in the multivariate models, including the age of the individuals and gestational age. For all the statistical analyses, a $P$-value of less than 0.05 was considered significant. Statistical Package for SPSS version 16.0 for windows was used for all the statistical analysis.

\section{Ethical issues}

Strict ethical guidelines were followed, because this study involved human subjects, namely pregnant women. The questionnaire was developed in a way that decidedly avoided collecting any information unrelated to the objectives of the study. Written informed consent was obtained from each pregnant woman after explanation of the intentions of the research. Confidentiality and anonymity of the pregnant women were maintained throughout the study. Besides these, ethical approval of the study was taken from the academic ethical review committee of the Department of Nutrition and Food Technology of Jessore University of Science and Technology, Bangladesh. 


\section{Results}

\section{Characteristics of the pregnant women}

A total of 717 pregnant women were included in the final analysis. Socio-demographic and physiological characteristics of these pregnant women are summarised in Table 1. The mean age of the pregnant women was about 24 years and mean gestational age was 6.56 months. About $47 \%$ of the pregnant women were from a family with five or more members. The total monthly income of $37 \%$ of the households was less than 5,000 BDT (62.5 USD). $33.68 \%$ of women who had enrolled in schools continued their education up to Secondary School Certificate (SSC) level but did not complete this level. All of the pregnant women were housewives and most of them (64.57 \%) were Muslim.

\section{Dietary phytate, calcium, iron and zinc intakes}

Dietary intake of phytate (Table 2), phytate density (mg per $1000 \mathrm{kcal}$ of energy intake), calcium, iron, and zinc intake (Fig. 1) of the pregnant women are reported based on quintiles of phytate intake. The mean dietary intake of phytate, calcium, iron, and zinc were found to be approximately 695.1, 192.2, 5.1, and $5.7 \mathrm{mg} /$ day, respectively.

Table 1 Characteristics of the pregnant women $(n=717)$

\begin{tabular}{|c|c|}
\hline Characteristics & Percent allocation \\
\hline \multicolumn{2}{|l|}{ Age } \\
\hline $18-22$ years & 45.05 \\
\hline $23-30$ years & 44.35 \\
\hline Above 30 & 10.60 \\
\hline \multicolumn{2}{|l|}{ Trimester } \\
\hline $2^{\text {nd }}$ Trimester & 45.89 \\
\hline $3^{\text {rd }}$ Trimester & 54.11 \\
\hline \multicolumn{2}{|l|}{ Household size } \\
\hline Less or equal to 3 & 17.85 \\
\hline 4 members & 28.87 \\
\hline 5 members or more & 46.72 \\
\hline \multicolumn{2}{|l|}{ Level of education } \\
\hline No education & 21.20 \\
\hline Less than primary & 17.71 \\
\hline Completed primary & 27.41 \\
\hline Less than SSC $^{a}$ & 33.68 \\
\hline \multicolumn{2}{|c|}{ Household level income $\left(\mathrm{BDT}^{\mathrm{b}}\right)$} \\
\hline Less than 5000 & 36.68 \\
\hline $5000-7000$ & 30.13 \\
\hline $7000-10000$ & 21.62 \\
\hline More than 10000 & 11.51 \\
\hline \multicolumn{2}{|l|}{ Religion } \\
\hline Islam & 64.57 \\
\hline Hinduism & 35.43 \\
\hline
\end{tabular}

${ }^{\mathrm{a}}$ Secondary School Certificate, ${ }^{\mathrm{b}}$ Bangladeshi Taka (1 USD $=80$ BDT)
Considering the variation of energy consumption of the pregnant women, the mean phytate intake was $478 \mathrm{mg}$ per $1000 \mathrm{kcal}$ of energy consumption. Phytate intake was found to be significantly $(p<0.05)$ different across the quintiles (Table 2) and the mean daily phytate intake ranged from $409.5 \mathrm{mg}$ ( $1^{\text {st }}$ quintile: the lowest intake group) to $888.2 \mathrm{mg}$ ( $5^{\text {th }}$ quintile: the highest intake group). Average daily calcium, iron and zinc intake ranged from 173.3 to $237.7 \mathrm{mg}, 3.9$ to $5.7 \mathrm{mg}$, and 5.3 to $6.9 \mathrm{mg}$ respectively across the quintiles.

\section{Phytate to minerals molar ratios}

The effects of phytate intake on the bioavailability of calcium, iron, and zinc from the diet of pregnant women are presented in terms of phytate to minerals molar ratios in Table 2. The proportions of pregnant women with ratios above the suggested critical values, segregated by phytate intake quintile, are also obtainable from Table 2. The mean molar ratios of phytate to calcium, iron, zinc and (phytate $\times$ calcium) to zinc were $0.27,12.4,11.8$, and 54.8 , respectively. All the molar ratios were found to be significantly $(p<0.05)$ higher in the highest phytate intake group ( $5^{\text {th }}$ quintile) compared to the other groups. Phytate to iron and zinc molar ratios were found to be significantly $(p<0.05)$ different across the quintiles. Mean phytate to iron and zinc molar ratios of a quintile were significantly $(p<0.05)$ higher than its preceding quintiles. All the molar ratios increased gradually from the lowest $\left(1^{\text {st }}\right.$ quintile) to highest ( $5^{\text {th }}$ quintile) quintiles.

The phytate to calcium molar ratios of $52 \%$ of the pregnant women were above the proposed decisive value. The proportions of women with phytate to calcium molar ratios above the critical value were increased by $21,59,84$, and 94 percentage points with the increasing intake of phytate across the quintiles. All the pregnant women had phytate to iron molar ratios above the cut-off value of 1 , irrespective of lowest to highest phytate intake groups. The mean values for phytate to iron molar ratios ranged from 7.9 to 17.9 across the quintiles. About $12 \%$ of the pregnant women had phytate to zinc molar ratios that exceeded the proposed critical value. In the highest phytate intake group, about $43 \%$, pregnant women had phytate to zinc molar ratios above the critical value. None of the pregnant women had (phytate $\times$ calcium) to zinc molar ratios higher than the critical value of 200 .

\section{Predictors of molar ratios}

In all the multivariate models, phytate to calcium, iron and zinc molar ratios were found to be positively associated with phytate intake and gestational age of the pregnant women (Table 3). The models for phytate to calcium, iron, and zinc molar ratios respectively explained $92 \%$, $88 \%$, and $89 \%$ of variance in molar ratios. The phytate to calcium molar ratio was negatively associated with calcium 
Table 2 Dietary phytate intake and molar ratios of dietary phytate to calcium, iron, zinc, and (phytate $\times$ calcium): zinc based on quintiles of phytate intake level

\begin{tabular}{|c|c|c|c|c|c|c|c|c|c|c|c|c|c|c|}
\hline \multirow{2}{*}{$\begin{array}{l}\text { Quintiles of } \\
\text { phytate intakes }\end{array}$} & \multicolumn{2}{|c|}{ hytate (mg/day) } & \multicolumn{3}{|c|}{ Phytate: Calcium } & \multicolumn{3}{|c|}{ Phytate: Iron } & \multicolumn{3}{|c|}{ Phytate: Zinc } & \multicolumn{3}{|c|}{ (Phytate $\times$ Calcium): Zinc } \\
\hline & $\overline{M e a n}$ & -1) & ean & -1) & & lean & 1) & & ean & $(95 \% C l)$ & & ean & 1) & $>20$ \\
\hline & & 1) & & 7) & 0.0 & & & 10 & & $(7$. & 0.0 & & & 0.0 \\
\hline $\mathrm{d} Q$ & 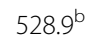 & $23.4-534.5)$ & & $.22-0.24)$ & م२ & & $24-0$ (2) & 100 & & $(9.1-9.5)$ & مिم & & & 0.0 \\
\hline $\mathrm{Qu}$ & & & & & & & & 1 & & & & & & 0.0 \\
\hline ${ }^{h}$ Quintile & . & $(768.5-778.1)$ & 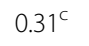 & $(0.30-0.32)$ & 85.3 & & ) & 100 & $13.6^{d}$ & ) & 16.8 & & & 0.0 \\
\hline & & 368.2-908.5) & & $(0.33-0.35)$ & 9 & & ) & 11 & & 11 & 4 & & 35.5) & 0.0 \\
\hline tal $(n=717)$ & 95.1 & (680.9-709.3) & 21 & $(0.26-0.28)$ & 52.0 & 12.0 & $(12.5-13.1)$ & 100 & 11.2 & (11.0-11.4) & 12.0 & S.ד. & (53.0-56.6) & 0 \\
\hline
\end{tabular}

${ }^{1}$ Values are given in percentage

${ }^{2}$ Analysis of variance (ANOVA) is performed with Games-Howell post hoc analysis to compare the effects of different quintiles categories of phytate intake. Values not sharing the same letters (a-e) denote significant difference among levels $(P<0.05)$

${ }^{3}$ All the quintiles contain an equal number of sample $(n=143)$ except the $3^{\text {rd }}$ quintile $(n=145)$

and zinc intake, whereas the phytate to iron molar ratio was found to be negatively associated with iron intake, but positively associated with zinc and calcium intake. Phytate to zinc molar ratios were also found to be negatively associated with zinc and calcium intake among the pregnant women (Table 3).

\section{Discussion}

A few prior studies [39, 40] in Bangladesh have documented the daily phytate intake of women in their typical consumed diet. However, there is no study that reports phytate intake and its effect on the bioavailability of major micronutrients from the typical diet of pregnant women in Bangladesh. Even the two randomized trials, involving pregnant women in Bangladesh, (JiVitA-3 [41] and MINIMat [42]), which investigated effects of maternal multiple micronutrients [41, 42] and early food supplementation [42] on maternal hemoglobin [42], birth weight
[41, 42], infant mortality [41, 42], and adverse birth outcomes [41, 42], have not reported the phytate intake of the studied pregnant women and its effect on the bioavailability of minerals from maternal diet.

\section{Dietary phytate intake}

Previous studies found a wide variation in phytate intake among the diets of rural women of Bangladesh. For example, Bhargava et al. [39] reported a very high mean daily phytate intake (around $2300 \mathrm{mg}$ ), whereas Arsenault et al. [40], in another study, reported phytate intake of approximately $650 \mathrm{mg}$. The wide difference in daily phytate intake between these two studies was probably due to the variations in energy intake among the studied rural women. In our study, we found that the average phytate intake of the rural pregnant women was $695 \mathrm{mg}$; this finding is in agreement with Arsenault et al.'s reported phytate intake of rural women in Bangladesh [40].

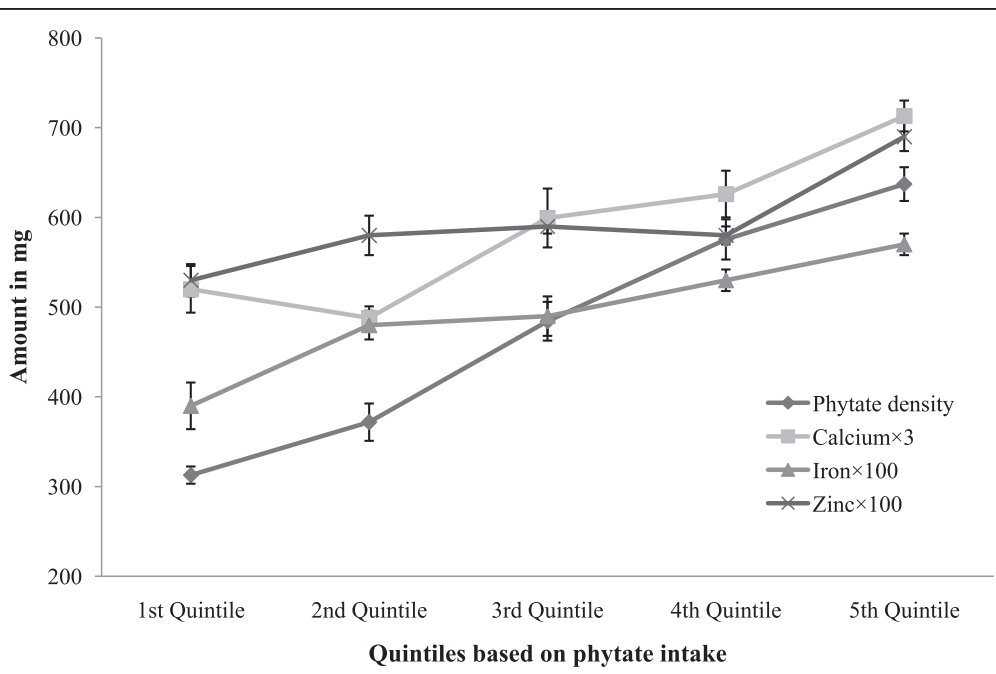

Fig. 1 Phytate density and dietary intake of calcium, iron, and zinc among the pregnant women. Mean \pm SEM values are given 
Table 3 Determinants of phytate to calcium, iron, and zinc molar ratios ${ }^{a}$

\begin{tabular}{|c|c|c|c|c|c|}
\hline \multicolumn{6}{|l|}{ Multivariate models ${ }^{b}$} \\
\hline & $B$ & $95 \% \mathrm{Cl}$ of $\mathrm{B}$ & SE (B) & $\beta$ & $P$ \\
\hline \multicolumn{6}{|l|}{ Phytate: Calcium } \\
\hline Age (year) & 0.008 & $0.007-0.009$ & 0.001 & 0.248 & $<0.001$ \\
\hline Gestational age (month) & 0.004 & $0.003-0.005$ & 0.001 & 0.053 & $<0.001$ \\
\hline Phytate(per 100 mg) & 0.048 & $0.046-0.052$ & 0.001 & 0.745 & $<0.001$ \\
\hline Energy (per 100 C) & 0.012 & $0.010-0.014$ & 0.001 & 0.233 & $<0.001$ \\
\hline Calcium (mg) & -0.003 & $-(0.004-0.002)$ & 0.001 & -0.842 & $<0.001$ \\
\hline Zinc (mg) & -0.007 & $-(0.010-0.004)$ & 0.002 & -0.071 & $<0.001$ \\
\hline Iron (mg) & -- & - & -— & -- & -- \\
\hline Intercept & -0.030 & $-(0.060-0.001)$ & 0.015 & -— & 0.013 \\
\hline Adjusted $R^{b}$ & 0.919 & & & & \\
\hline \multicolumn{6}{|l|}{ Phytate: Iron } \\
\hline Age (year) & 0.130 & $0.091-0.169$ & 0.021 & 0.095 & $<0.001$ \\
\hline Gestational age (month) & 0.132 & $0.184-0.179$ & 0.024 & 0.044 & 0.022 \\
\hline Phytate (per 100 mg) & 2.476 & $2.377-2.574$ & 0.051 & 0.853 & $<0.001$ \\
\hline Energy (per 100 C) & -0.171 & $-(0.203-0.139)$ & 0.016 & -0.079 & 0.015 \\
\hline Calcium (mg) & 0.006 & $0.005-0.007$ & 0.001 & 0.109 & $<0.001$ \\
\hline Zinc (mg) & 0.542 & $0.439-0.645$ & 0.052 & 0.132 & $<0.001$ \\
\hline Iron (mg) & -2.122 & $-(2.186-2.058)$ & 0.033 & -0.551 & $<0.001$ \\
\hline Intercept & 6.759 & $5.941-7.576$ & 0.743 & -- & $<0.001$ \\
\hline Adjusted $R^{b}$ & 0.881 & & & & \\
\hline \multicolumn{6}{|l|}{ Phytate: Zinc } \\
\hline Age (year) & - & -- & - & -- & -- \\
\hline Gestational age (month) & 0.197 & $0.146-0.247$ & 0.026 & 0.110 & $<0.001$ \\
\hline Phytate (per 100 mg) & 1.956 & $1.897-2.015$ & 0.030 & 0.967 & $<0.001$ \\
\hline Energy (per 100 C) & -0.031 & $-(0.053-0.010)$ & 0.011 & -0.035 & $<0.001$ \\
\hline Calcium (mg) & -0.003 & $-(0.004-0.002)$ & 0.001 & -0.085 & $<0.001$ \\
\hline Zinc (mg) & -0.825 & $-(0.931-0.720)$ & 0.054 & -0.339 & $<0.001$ \\
\hline Iron (mg) & -- & - & - & -— & -- \\
\hline Intercept & 9.358 & $8.991-9.725$ & 0.187 & -— & $<0.001$ \\
\hline Adjusted $R^{b}$ & 0.888 & & & & \\
\hline
\end{tabular}

${ }^{a}$ Models included 717 pregnant women. Dash indicates the variables were not included in the model due to insignificance

${ }^{b}$ Linear regression models with phytate to calcium, iron, and zinc molar ratios as the dependent variables and the independent variables that remained significant on the models, $P<0.05$

The average daily phytate intake among rural pregnant women in our study was lower than that in Ethiopia [43] and Guatemala [19], while it was reported that the women of childbearing age in Sweden [44], Italy [24] and Finland [24] consumed about $180 \mathrm{mg}, 293 \mathrm{mg}$, and $370 \mathrm{mg}$ of phytate per day, respectively. A few studies on women in other Asian countries indicate that average phytate intake is higher compared to Western countries. Taiwan has reported an average phytate intake of $690 \mathrm{mg} /$ day [45], whereas Indian women consume as much as 1560-2500 mg of phytate per day. Nititham et al.
[46] reported that the daily phytate intake of non-urban women in Thailand was $1139 \mathrm{mg}$, while women in South Korea [47] showed phytate intakes of $752 \mathrm{mg} /$ day.

\section{Phytate to minerals molar ratios for bioavailability}

This study focuses on diet-related factors, especially the inhibitory effect of phytate on calcium, iron and zinc bioavailability from the consumed diet of rural pregnant women in Bangladesh. The influence of phytate on the bioavailability of essential micronutrients depends not only on the phytate contents of the diet, but also the 
phytate and micronutrients' interaction. We have used phytate to minerals molar ratios to forecast the inhibitory effect of phytate on the bioavailability of minerals from the consumed diet of the pregnant women [18, 19, 23, 25]. Moreover, we have used cut-off values for each of the molar ratios to identify the proportion of pregnant women affected by the inhibitory effects of phytate intake on calcium, iron and zinc bioavailability. We have reported the mean phytate to minerals molar ratios and further segregated the molar ratios by quintiles of phytate intake from the diet. All the molar ratios in our study were found to increase with the concomitant increment of phytate intake across the quintiles.

The mean phytate to calcium molar ratio was found to be 0.27 in our study, which is more than the critical value $(>0.24)$ to impair calcium absorption. The effect of phytate intake on calcium bioavailability among the women of Bangladesh has not been studied or reported yet. In our study, we found that more than half of the pregnant women have phytate to calcium molar ratio above the critical value, which indicates that the calcium bioavailability of this proportion of women was affected by phytate intake. Low bioavailability of calcium from the diet of the pregnant women might have resulted in low total serum calcium level. Though in our study we had not measured the serum calcium levels of our studied pregnant women, the available literature has shown low to marginal levels of serum calcium in the pregnant women of Bangladesh [11-13].

We have not found any study which reports the phytate to iron molar ratios of pregnant women in Bangladesh. Mean phytate to iron molar ratio of the rural pregnant women of Bangladesh was reported to be 12.8 in our study. In addition, the mean phytate to iron molar ratio was found to be significantly $(p<0.05)$ higher in the highest phytate intake group compared to other groups. Across all the groups, the mean phytate to iron molar ratios was higher than the cut-off value. The cut-off value of phytate: iron $>1$ will significantly reduce iron absorption from the diet [35]. Considering the cut-off value, dietary iron among all the pregnant women in our study was inhibited by phytate intake. Due to the lack of biochemical data for serum iron status, we have failed to correlate and translate these findings to the extent of iron deficiency.

The mean phytate to zinc molar ratio of the rural pregnant women in our study was 11.2, which is soundly supported by findings from Arsenault et al. who studied women in rural Bangladesh [40]. Besides this, the 2011-12 Bangladesh National Micronutrient Status Survey [14] has reported a mean phytate to zinc molar ratio of 12.0 among rural Non Pregnant Non Lactating (NPNL) women in Bangladesh. The reported ratio in our study was lower than that of pregnant women in Guatemala [19] and China [48], but higher than young Korean women [49].
Unlike phytate to iron and calcium molar ratios, the mean phytate to zinc molar ratio in our studied pregnant women was lower than the cut-off value. Our data propose that phytate affects zinc bioavailability on $12 \%$ of the rural pregnant women sampled. Though the phytate has little effect on zinc absorption in our studied pregnant women, the available literature on women from Bangladesh has demonstrated a very high prevalence of zinc deficiency. The prevalence of zinc deficiency among rural NPNL women of Bangladesh was reported to be $57.5 \%$, while mean phytate to zinc molar ratios were found to be 12.0 among these women [14]. This high prevalence of zinc deficiency was probably due to the inadequate intake (54.2\% of RDA) of zinc among the women, and phytate to some extent affects the bioavailability of zinc. However, the mean phytate to zinc molar ratio of the pregnant women's diet in our study was comparatively low. Inadequate total zinc intake, and to some extent, phytate, might have resulted in too little absorbable zinc from the diet [40]. Perhaps it is necessary to redefine the cut-off value of phytate to zinc molar ratio among women in Bangladesh.

The molar ratio of (phytate $\times$ calcium) to zinc was used to predict the synergistic effect of both phytate and calcium on zinc absorption [37, 50]. When considering the low calcium intake of the rural pregnant women, (phytate $\times$ calcium) to zinc molar ratio might not be a good indicator for predicting the interaction of phytate and calcium to zinc absorption [23]. In our study, we found that none of the women had (phytate $\times$ calcium) to zinc molar ratio $>200$.

\section{Predictors of calcium, iron, and zinc bioavailability}

As we have mentioned earlier, we measured the inhibitory effects of phytate intake on the bioavailability of calcium, iron and zinc from the diet of the pregnant women on the basis of phytate to minerals molar ratios. Moreover, we have tried to find out the determinants that significantly predict the variance in molar ratios, and hence the bioavailability of calcium, iron, and zinc from the diet. From the multivariate models we have used in predicting the inhibitory effects of phytate intake on the bioavailability of calcium, iron and zinc, we would like to infer that four predictors - namely, phytate intake, inadequate micronutrient intake, gestational age, and energy intake - significantly predicted the variance in phytate to minerals molar ratios. Our models have predicted about $92 \%, 88 \%$, and $89 \%$ of variance in phytate to calcium, iron, and zinc molar ratios, respectively.

Among these predictors, phytate was the strongest inhibitory predictor of calcium, iron and zinc bioavailability from the diets of pregnant women. The inhibitory effect of phytate on bioavailability increases with the increment of phytate intake. In our study, we found that phytate to calcium, iron, and zinc molar ratios would be 
expected to be respectively $0.05,2.48$, and 1.96 points higher for every $100 \mathrm{mg}$ increment in daily phytate intake. The explanation for these findings could be that plant based foods consumed by the pregnant women in Bangladesh $[14,15,51]$ contain high level of phytate, which is known as a potent inhibitor of calcium, iron and zinc absorption [18]. Phytate chelates calcium, iron and zinc, forming insoluble chemical complexes in the gastrointestinal tract that cannot be digested or absorbed [20], and thus makes these minerals not available for absorption; rather, they are probably excreted through faeces with minerals-phytate complexes [52].

Another strong inhibitory predictor of the bioavailability of the micronutrients was inadequate intake of calcium, iron and zinc in the diets of these pregnant women. Inadequate intake of calcium, iron and zinc reduce the efficiency of absorption of these minerals from the diet by reducing minerals-receptors complexes and/or available amount of minerals for absorption [52-54]. Arsenault et al. had reported that respectively 0,16 and 22 percent of rural Bangladeshi women displayed adequate calcium, iron, and zinc intake [51]. Inadequate intake of calcium, iron and zinc among these women and the pregnant women in our study was due to the consumption of a major portion of their daily energy intake from white rice [51], which is relatively very low in calcium, iron, and zinc [29]. In addition, the dietary patterns of pregnant women in low-resource settings are characterised by a lack of diversity, with infrequent consumption of nutrient-rich foods and milk and milk products $[5,55,56]$.

Our study has also shown that gestational age has a significant effect on the bioavailability of zinc, iron, and calcium. Women who were close to the end of their pregnancies had higher phytate to zinc, iron and calcium molar ratios. This effect might be due to the inadequate intake of zinc, iron, and calcium of the pregnant women compared to the increasing needs for these micronutrients as pregnancy progresses [57]. As pregnancy proceeds, an alarmingly high number of pregnant women of Bangladesh claim to eat less than pre-pregnancy levels [58].

\section{Limitations to the study}

A major limitation of this study was that the dietary assessment of the pregnant women was collected using a single 24-h dietary recall. Although one 24-h recall is sufficient to provide estimates of the average nutrient intake of a large sample, the day to day variation in intake might provide random errors in the average nutrient intake. Hence, it was not possible to conclude with assurance that the phytate and micronutrients intake of the pregnant women represented their habitual intake.

However, the available literature regarding the micronutrient intake of pregnant and NPNL women of Bangladesh are well aligned with our findings. Besides, other studies from Bangladesh have reported the seasonal variations in micronutrient intake of women. Therefore, the collection of data concerning a single point in time has boundaries to depict the accurate picture of phytate and micronutrient intake of the pregnant women over the whole gestational period.

A further limitation of our study is that we have not collected the biochemical data of the pregnant women. Due to the lack of biochemical data regarding the serum concentrations of calcium, iron and zinc, we are unable to correlate the molar ratios with biochemical deficiencies of these minerals.

\section{Conclusions}

In summary, for the very first time, this study reports the phytate intake and its consequence on the bioavailability of calcium, iron and zinc from the diets of pregnant women in rural Bangladesh. The study concludes that the phytate intake of the sampled women was higher compared to women of developed countries, but lowers than the reported intake in other developing countries. Phytate inhibits the bioavailability of iron from the diet of all the pregnant women and inhibits calcium absorption among more than half of the pregnant women. An inhibiting effect of phytate on zinc absorption was not found in a notable number of pregnant women.

From the multivariate analyses, we found that phytate intake, low micronutrients intake, gestational age, and energy intake of the sampled pregnant women were all significantly associated with the bioavailability of calcium, iron and zinc from the diet. Among those associated predictors, phytate was the strongest inhibitory predictor of calcium, iron and zinc bioavailability. Phytate to calcium, iron, and zinc molar ratios would be expected to be respectively $0.05,2.48$, and 1.96 points higher for every $100 \mathrm{mg}$ increment in daily phytate intake.

This scenario points to an urgent call for addressing the problems associated with poor mineral bioavailability from the diet of rural pregnant women in Bangladesh due to high phytate intake. The effect of phytate intake on the bioavailability of minerals means their micronutrient consumption may fail to meet their mineral needs. However, even when the high phytate diets of the pregnant women are supplemented and/or fortified with minerals, the supplementation and/or fortification might not ensure the increasing needs of the pregnant women.

\section{Availability of data and materials}

We are unable to share our dataset for now. We are planning to submit another research work by using this dataset; hence, our dataset will not be shared. 


\section{Additional file}

Additional file 1: English version of the questionnaire. (PDF $212 \mathrm{~kb}$ )

\section{Abbreviations}

ANOVA: analysis of variance; C: kilocalories; CC: community clinic; Cl: confidence interval; FCT: food composition table; JiVitA: a maternal and child health and nutrition research project in Bangladesh; MINIMat: maternal and infant nutrition interventions in Matlab; MPR: multiple pass recall; NPNL: non-pregnant non-lactating; RDA: recommended dietary allowance; SEM: standard error of the mean; SSC: secondary school certificate.

\section{Competing interests}

The authors declare that they have no competing interests.

\section{Authors' contributions}

SMAH participated in study protocol development, data collection, data analysis, write-up and drafting of the manuscript. MMH, SS, MMI, and MMB assisted in protocol development, data collection, data entry, data coding, data editing, data analysis and write up. MSI assisted in writing up the revised manuscript and data analysis. All authors read and approved the final manuscript.

\section{Acknowledgements}

We gratefully acknowledge the contribution of our respected reviewers whose priceless suggestions assist us to restructure the entire manuscript we are really thankful to them, they made us where we are now. We wish to express our immense gratitude to "Laura" and "Md. Masud Rana" for their intellectual and bighearted assist in writing the revised manuscript. We also thankfully acknowledge the contribution of Safia Tasnim, Joyosree Roy Chowdhury, Abdur Rahman and Payel Halder for their kind help in writing the revised manuscripts. We also gratefully acknowledge the following wonderful persons who participated in various aspects of the research process: Md. Al-Nasim, Nahidul Islam, Md. Sohel Rana, MD. Nasir Uddin Badal, Md. Sheikh Shahriar Rajib, Md. Firoz Mahmud, MD. Rayhan Kabir, Rasel Ahmed, Md. Salek Khan, and Md. Shafiqul Islam. We also thankful to Md. Nazmul Hossain, Mst. Ayesha Aktar, Md. Shameem Ahmed, Md. Ismail Hossen, Md. Arif Hossain, Selim Reza, Md. Masud Hossain, Shakil Ahmed, Suvra Nag, Saleha Sultana, Md. Mamun-Or-Rasid Joy, Shipra Sarker, Shoheli Nazmin, Sharmin Pervin, Tarek Hasan, Shemeen Ahmed, Sharmin Sultana, Sadia Afrin, Md. Kamruzzaman Khan, Md. Nazmul Hossain, Tanzina Tasmin, and Trapa Paul. Last but not the least, special thanks go to entire study subjects for their full participation in the study. This study was funded by some of the graduate students of the Department of Nutrition and Food Technology of Jessore University of Science and Technology, Bangladesh.

Received: 8 March 2015 Accepted: 19 April 2016

Published online: 21 April 2016

\section{References}

1. Picciano MF. Pregnancy and lactation: physiological adjustments, nutritional requirements and the role of dietary supplements. J Nutr. 2003;133:1997S-2002. Available from: http://www.ncbi.nlm.nih.gov/pubmed/12771353.

2. Ramakrishnan U, Grant FK, Goldenberg T, Bui V, Imdad A, Bhutta ZA. Effect of multiple micronutrient supplementation on pregnancy and infant outcomes: a systematic review. Paediatr Perinat Epidemiol. 2012;26 Suppl 1: 153-67. Available from: http://www.ncbi.n/m.nih.gov/pubmed/22742608.

3. Black RE, Victora CG, Walker SP, Bhutta ZA, Christian P, de Onis M, et al. Maternal and child undernutrition and overweight in low-income and middle-income countries. Lancet. 2013;382:427-51. Available from: http://www.ncbi.nlm.nih.gov/pubmed/23746772.

4. Uriu-Adams J, Keen C. Zinc and reproduction: effects of zinc deficiency on prenatal and early postnatal development. Birth Defects Res B Dev Reprod Toxicol. 2010;89:313-25. Available from: http://www.ncbi.nlm.nih.gov/ pubmed/20803691.

5. Torheim LE, Ferguson EL, Penrose K, Arimond M. Women in resource-poor settings are at risk of inadequate intakes of multiple micronutrients. J Nutr. 2010;140:2051S-8. Available from: http://www.ncbi.nlm.nih.gov/pubmed/ 20881075.

6. Andersen LT, Thilsted SH, Nielsen BB, Rangasamy S. Food and nutrient intakes among pregnant women in rural Tamil Nadu, South India. Public
Health Nutr. 2003;6:131-7. Available from: http://www.ncbi.nlm.nih.gov/ pubmed/12675955.

7. Jiang T, Christian P, Khatry SK, Wu L, West KP. Micronutrient deficiencies in early pregnancy are common, concurrent, and vary by season among rural Nepali pregnant women. J Nutr. 2005;135:1106-12. Available from: http:// www.ncbi.nlm.nih.gov/pubmed/15867289.

8. Gautam VP, Taneja DK, Sharma N, Gupta VK, Ingle GK. Dietary aspects of pregnant women in rural areas of Northern India. Matern Child Nutr. 2008;4: 86-94. Available from: http://www.ncbi.nlm.nih.gov/pubmed/18336642.

9. Samuel TM, Thomas T, Finkelstein J, Bosch R, Rajendran R, Virtanen SM, et al. Correlates of anaemia in pregnant urban South Indian women: a possible role of dietary intake of nutrients that inhibit iron absorption. Public Health Nutr. 2013;16:316-24. Available from: http://www.pubmedcentral.nih.gov/ articlerender.fcgi?artid=3713478\&tool=pmcentrez\&rendertype=abstract.

10. Islam MZ, Lamberg-Allardt C, Kärkkäinen M, Ali SMK. Dietary calcium intake in premenopausal Bangladeshi women: do socio-economic or physiological factors play a role? Eur J Clin Nutr. 2003;57:674-80. Available from: http:// www.ncbi.nlm.nih.gov/pubmed/12771968.

11. Akhter K, Rahman MS, Ahmed S, Ahmed A, Alam SM. Serum calcium in normal pregnant women. Mymensingh Med J. 2003;12:55-7. Available from: http://www.ncbi.n/m.nih.gov/pubmed/12715646.

12. Sultana MS, Begum R, Akhter QS, Lovely NS, Akhter S, Islam MT. Serum calcium and phosphate level in normal pregnant women. Bangladesh J Med Sci. 2012;11:21720. Available from: http://www.banglajol.info/index.php/BJMS/article/view/11732.

13. Roth DE, Pezzack B, Al Mahmud A, Abrams SA, Islam M, Aimone Phillips A, et al. Bioavailability of enteric-coated microencapsulated calcium during pregnancy: a randomized crossover trial in Bangladesh. Am J Clin Nutr. 2014; 100:1587-95. Available from: http://www.ncbi.nlm.nih.gov/pubmed/25411294.

14. icddr,b, UNICEF, GAIN, IPHN. National Micronutrients Status Survey 2011-12. Dhaka, Bangladesh: icddr,b and UNICEF, Bangladesh; 2013. http://files. givewell.org/files/DWDA\%202009/GAIN/ Bangladesh\%20National\%20Micronutrient\%20Survey\%202013.pdf.

15. Merrill RD, Shamim AA, Ali H, Jahan N, Labrique AB, Schulze K, et al. Iron status of women is associated with the iron concentration of potable groundwater in rural Bangladesh. J Nutr. 2011;141:944-9. Available from: http://www.ncbi.nlm.nih.gov/pubmed/21451130.

16. Khambalia A, O'Connor DL, Zlotkin S. Periconceptional iron and folate status is inadequate among married, nulliparous women in rural Bangladesh. J Nutr. 2009. 139:1179-84. Available from: http://www.ncbi.nlm.nih.gov/pubmed/19403710.

17. Tetens I, Hels O, Khan NI, Thilsted SH, Hassan N. Rice-based diets in rural Bangladesh: how do different age and sex groups adapt to seasonal changes in energy intake? Am J Clin Nutr. 2003;78:406-13. Available from: http://www.ncbi.nlm.nih.gov/pubmed/12936922.

18. Gibson RS, Bailey KB, Gibbs M, Ferguson EL. A review of phytate, iron, zinc, and calcium concentrations in plant-based complementary foods used in I ow-income countries and implications for bioavailability. Food Nutr Bull. 2010; 31:S134-46. Available from: http://www.ncbi.nlm.nih.gov/pubmed/20715598.

19. Fitzgerald SL, Gibson RS, Quan de Serrano J, Portocarrero L, Vasquez A, de Zepeda $\mathrm{E}$, et al. Trace element intakes and dietary phytate/Zn and $\mathrm{Ca}$ phytate/Zn millimolar ratios of periurban Guatemalan women during the third trimester of pregnancy. Am J Clin Nutr. 1993:57:195-201.

20. lqbal TH, Lewis $\mathrm{KO}$, Cooper BT. Phytase activity in the human and rat small intestine. Gut. 1994;35:1233-6. Available from: http://www.pubmedcentral.nih. gov/articlerender.fcgi?artid=1375699\&tool=pmcentrez\&rendertype=abstract.

21. Lönnerdal B. Dietary factors influencing zinc absorption. J Nutr. 2000;130: 1378S-83. Available from: http://www.ncbi.nlm.nih.gov/pubmed/10801947.

22. Egli I, Davidsson L, Zeder C, Walczyk T, Hurrell R. Dephytinization of a complementary food based on wheat and soy increases zinc, but not copper, apparent absorption in adults. J Nutr. 2004;134:1077-80. Available from: http://www.ncbi.nlm.nih.gov/pubmed/15113948.

23. Ma G, Li Y, Jin Y, Zhai F, Kok FJ, Yang X. Phytate intake and molar ratios of phytate to zinc, iron and calcium in the diets of people in China. Eur J Clin Nutr. 2007;61:368-74. Available from: http://www.ncbi.nlm.nih.gov/pubmed/16929240.

24. Schlemmer U, Frølich W, Prieto RM, Grases F. Phytate in foods and significance for humans: food sources, intake, processing, bioavailability, protective role and analysis. Mol Nutr Food Res. 2009;53 Suppl 2:S330-75. Available from: http://www.ncbi.nlm.nih.gov/pubmed/19774556.

25. Amirabdollahian F, Ash R. An estimate of phytate intake and molar ratio of phytate to zinc in the diet of the people in the United Kingdom. Public Health Nutr. 2010;13:1380-8. Available from: http://www.ncbi.nlm.nih.gov/ pubmed/20409358. 
26. Raper N, Perloff B, Ingwersen L, Steinfeldt L, Anand J. An overview of USDA's Dietary Intake Data System.pdf. J Food Compos Anal. 2004;17:545-55. Available from: http://ac.els-cdn.com/S0889157504000511/1-s2.0-S0889157504000511main.pdf?_tid=38ca7396-288a-11e4-b96f-00000aacb360\&acdnat=1408553665_ 17df9f4984c2d96ac22e899bb5f9a25d.

27. Kruger R, Stonehouse W, Von Hurst PR, Coad J. Combining food records with in-depth probing interviews improves quality of dietary intake reporting in a group of South Asian women. Aust N Z J Public Health. 2012; 36:135-40. Available from: http://www.ncbi.nlm.nih.gov/pubmed/22487347.

28. Blanton CA, Moshfegh AJ, Baer DJ, Kretsch MJ. The USDA Automated Multiple-Pass Method accurately estimates group total energy and nutrient intake. J Nutr. 2006;136:2594-9. Available from: http://www.ncbi.nlm.nih. gov/pubmed/16988132.

29. Shaheen N, Rahim ATMA, Mohiduzzaman M, Banu CP, Bari ML, Tukun AB, et al. Food Composition Table for Bangladesh. First. Dhaka: Intergraphic Limited; 2013.

30. Reddy NR. Food Phytates. In: Reddy NR, Sathe SK, editors. Food Phytate. United States of America: CRC Press; 2002. p. 25-47. Available from: http:// books.google.com/books?hl=en\&lr=\&id=ifUkaCTmqpMC\&pgis=1.

31. Ravindran V, Ravindran G, Sivalogan S. Total and phytate phosphorus contents of various foods and feedstuffs of plant origin. Food Chem. 1994; 50:133-6. Available from: http://linkinghub.elsevier.com/retrieve/pii/ 0308814694901090.

32. Ferguson EL, Gibson RS, Thompson LU, Ounpuu S, Berry M. Phytate, zinc, and calcium contents of 30 East African foods and their calculated phytate: Zn, Ca:phytate, and [Ca] [phytate]/[Zn] molar ratios. J Food Compos Anal. 1988;1:316-25. Available from: http://www.sciencedirect.com/science/article/ pii/0889157588900312.

33. Harland BF, Oberleas D. Phytate in foods. World Rev Nutr Diet. 1987;52:235-59. Available from: http://www.ncbi.n/m.nih.gov/pubmed/3327233.

34. Morris ER, Ellis R. Nutritional Bioavailability of Calcium. Kies C, editor. Washington, D.C. American Chemical Society; 1985 [cited 2014 Aug 22]. Available from: http://dx.doi.org/10.1021/bk-1985-0275.ch006

35. Hallberg L, Brune M, Rossander L. Iron absorption in man: ascorbic acid and dose-dependent inhibition by phytate. Am J Clin Nutr. 1989;49:140-4. Available from: http://www.ncbi.n/m.nih.gov/pubmed/2911999.

36. Morris ER, Ellis R. Usefulness of the dietary phytic acid/zinc molar ratio as an index of zinc bioavailability to rats and humans. Biol Trace Elem Res. 1989; 19:107-17. Available from: http://www.ncbi.n/m.nih.gov/pubmed/2484373.

37. Gibson RS, Vanderkooy PDS, Thompson L. Dietary phytate $x$ calcium/zinc millimolar ratios and zinc nutriture in some Ontario preschool children. Biol Trace Elem Res. 1991;30:87-94. Available from: http://www.ncbi.nlm.nih.gov/ pubmed/1718372

38. Ghasemi A, Zahediasl S. Normality tests for statistical analysis: a guide for non-statisticians. Int J Endocrinol Metab. 2012;10:486-9. Available from: http://www.pubmedcentral.nih.gov/articlerender.fcgi?artid=3693611 \&tool=pmcentrez\&rendertype $=$ abstract.

39. Bhargava A, Bouis HE, Scrimshaw NS. Dietary intakes and socioeconomic factors are associated with the hemoglobin concentration of Bangladeshi women 1. J Nutr. 2001;131:758-64.

40. Arsenault JE, Yakes EA, Hossain MB, Islam MM, Ahmed T, Hotz C, et al. The current high prevalence of dietary zinc inadequacy among children and women in rural Bangladesh could be substantially ameliorated by zinc biofortification of rice. J Nutr. 2010;140:1683-90. Available from: http://jn. nutrition.org/content/140/9/1683.short.

41. West KP, Shamim AA, Mehra S, Labrique AB, Ali H, Shaikh S, et al. Effect of maternal multiple micronutrient vs iron-folic acid supplementation on infant mortality and adverse birth outcomes in rural Bangladesh: the JiVitA-3 randomized trial. JAMA. 2014;312:2649-58. Available from: http://www.ncbi. nlm.nih.gov/pubmed/25536256.

42. Persson LÅ, Arifeen S, Ekström E-C, Rasmussen KM, Frongillo EA, Yunus M. Effects of prenatal micronutrient and early food supplementation on maternal hemoglobin, birth weight, and infant mortality among children in Bangladesh: the MINIMat randomized trial. JAMA. 2012;307:2050-9. Available from: http://www.ncbi.n/m.nih.gov/pubmed/22665104.

43. Abebe Y, Bogale A, Hambidge KM, Stoecker BJ, Bailey K, Gibson RS. Phytate, zinc, iron and calcium content of selected raw and prepared foods consumed in rural Sidama, Southern Ethiopia, and implications for bioavailability. J Food Compos Anal. 2007;20:161-8. Available from: http://linkinghub.elsevier.com/ retrieve/pii/S0889157506001621.
44. Torelm I, Bruce A. Fytinsyra i livsmedel. Var foda. 1982;34:79-96. Available from: http://agris.fao.org/agris-search/search.do?recordID=US201302165335.

45. Wang CF, Tsay SM, Lee CY, Liu SM, Aras NK. Phytate content of Taiwanese diet determined by phosphorus-31 Fourier transform nuclear magnetic resonance spectroscopy. J Agric Food Chem. 1992;40:1030-3. doi:10.1021/ jf00018a023.

46. Nititham S, Srianujata S, Rujirawat T. Dietary intake of phytate, zinc and calcium of self-selected diets of Ubon Ratchathani and Bangkok subjects, Thailand. J Med Assoc Thai. 1999;82:855-61. Available from: http://www. ncbi.nlm.nih.gov/pubmed/10561940.

47. Joung H, Nam G, Yoon S, Lee J, Shim JE, Paik HY. Bioavailable zinc intake of Korean adults in relation to the phytate content of Korean foods. J Food Compos Anal. 2004;17:713-24. Available from: http://www.sciencedirect. com/science/article/pii/S0889157503001534.

48. Cheng Y, Dibley MJ, Zhang X, Zeng L, Yan H. Assessment of dietary intake among pregnant women in a rural area of western China. BMC Public Health. 2009;9:222. Available from: http://www.pubmedcentral.nih.gov/ articlerender.fcgi?artid=2716336\&tool=pmcentrez\&rendertype=abstract.

49. Shan JL, Kim J, Joung H, Paik HY. The Effect of Dietary Phytate Content on Iron Absorption and Status in Young Korean Women: Int. J. Hum. Ecol [Internet]. 2003 [cited 2014 Sep 6]; Available from: http://www.khea.or.kr/ InternationalJournal/2003/4-1/4.PDF .

50. Bindra GS, Gibson RS, Thompson LU. [Phytate] [calcium]/[zinc] ratios in Asian immigrant lacto-ovo vegetarian diets and their relationship to zinc nutriture. Nutr Res. 1986;6:475-83. Available from: http://www.sciencedirect. com/science/article/pii/S0271531786801014.

51. Arsenault JE, Yakes EA, Islam MM, Hossain MB, Ahmed T, Hotz C, et al. Very low adequacy of micronutrient intakes by young children and women in rural Bangladesh is primarily explained by low food intake and limited diversity. J Nutr. 2013;143:197-203. Available from: http://www.ncbi.nlm.nih. gov/pubmed/23256144

52. Miller LV, Krebs NF, Hambidge KM. A mathematical model of zinc absorption in humans as a function of dietary zinc and phytate. J Nutr. 2007;137:135-41. Available from: http://www.pubmedcentral.nih.gov/ articlerender.fcgi?artid=1995555\&tool=pmcentrez\&rendertype=abstract.

53. Andrews NC. Intestinal iron absorption: current concepts circa 2000. Dig Liver Dis. 2000;32:56-61. Available from: http://www.ncbi.nlm.nih.gov/ pubmed/10975756.

54. Fleet JC, Schoch RD. Molecular mechanisms for regulation of intestinal calcium absorption by vitamin D and other factors. Crit Rev Clin Lab Sc. 2010;47:181-95. Available from: http://www.pubmedcentral.nih.gov/ articlerender.fcgi?artid=3235806\&tool=pmcentrez\&rendertype=abstract.

55. Arimond M, Wiesmann D, Becquey E, Carriquiry A, Daniels M, Deitchler M, et al. Dietary diversity as a measure of the micronutrient adequacy of women's diets in resource-poor areas. Washington DC: Summary of Results from Five Sites; 2011.

56. Lee SE, Talegawkar SA, Merialdi M, Caulfield LE. Dietary intakes of women during pregnancy in low- and middle-income countries. Public Health Nutr. 2013;16:1340-53. Available from: http://www.ncbi.nlm.nih.gov/pubmed/ 23046556.

57. Butte NF, Wong WW, Treuth MS, Ellis KJ, O'Brian Smith E. Energy requirements during pregnancy based on total energy expenditure and energy deposition. Am J Clin Nutr. 2004;79:1078-87. Available from: http://www.ncbi.nlm.nih.gov/pubmed/15159239.

58. Helen Keller International (HKI). James P Grant School of Public Health (JPGSPH). Dhaka, BD: State of food security and nutrition in Bangladesh 2013; 2014. 